\title{
Blockchain Technology Transformation in Advancing Future Change
}

\author{
Taqwa Hariguna', Yusuf Durachman², Muhamad Yusup ${ }^{3}$, Shofiyul Millah $^{4}$ \\ University Amikom Purwokerto ${ }^{1}$, Syarif Hidayatullah State Islamic University Jakarta², \\ University of Raharja ${ }^{3,4}$ \\ Universitas Amikom Purwokerto, Jl. Letjen Pol Sumarto Watumas Purwanegara \\ Purwokerto ${ }^{1}$, Jl. Ir H. Juanda No.95, Cemp. Putih, Kota Tangerang Selatan ${ }^{2}$, Jl. Jenderal \\ Sudirman No.40, RT.002/RW.006, Cikokol, Kec. Tangerang, Kota Tangerang, Banten \\ $15117^{3,4}$ \\ e-mail: taqwa@amikompurwokerto.ac.id ${ }^{1}$, yusuf durachman@uinjkt.ac.id² ${ }^{2}$, \\ yusup@raharia.info 3 , shofiyul@raharia.info 4
}

\begin{abstract}
Hariguna, T. ., Durachman, Y. ., Yusup, M., \& Millah, S. (2021). Blockchain Technology Transformation in Advancing Future Change. Blockchain Frontier Technology, 1(01), 13-20. Retrieved from
\end{abstract}

DOI: https://journal.pandawan.id/b-front/article/view/4

\begin{abstract}
With the development of technology in the 4th century, it can be seen from before the christian period (SM) such as the compass, calendar, pozzolana and wheel. And now the world is about to undergo a tremendous transformation. In this extraordinary change there are inventions such as printing machines, machines, digital computers, vaccines, telegraph technology, ironing tools, airplanes, and even the internet. With this discovery, the world underwent a tremendous transformation from the previous century, due to technological advances over time. Inventions made before Christ must take a long time, even centuries, but making changes today only takes a few years. But in this study, we will describe blockchain technology even centuries, but by making changes now it only takes a few years. But this research will describe blockchain technology. On Facebook, which has a new change to the concept of decentralization, but this concept is still somewhat contradictory to the current world system, so why do users need intermediaries, namely third parties to keep the transaction secure? This research will provide answers to arguments starting with a conceptual understanding which will then go through the stage of case study stages in various industries such as administration, banking, chain management, intellectual management, transportation, even asset management, logistics and energy materials. With blockchain technology, it is used to describe blockchain technology and technology that humans do everyday. There is a concept of a ledger that undergoes a gradual transformation carried out by Satoshi Nakamoto, who has a triple entry ledger that is used to master blockchain technology. In blockchain technology, it has cryptography that is useful for avoiding money laundering, knowing customer activity, knowing all banking transactions and even administration in storing people's identities. In this case study, we will discuss big companies such as IBM, Amazon, Maersk, and even a kind of startup like Ezremit and Signazy. And in this administration section it is important to identify global educational techniques and develop technology in a better direction so that it can advance society in Indonesia and blockchain technology is included in technology that advances future change.
\end{abstract}

Keywords: Blockchain, immutable ledger, decentralized systems.

\section{Introduction}

Blockchain technology is a new invention, the blockchain technology has three different fields, such as decentralized networks, deliberation, and cryptographic methods [1]. The part that is contained in a decentralized network is the center in a computer network [2]. The 
protocols used are multiple computer sequences, neural circuits and various types of machine learning. Besides the existence of a decentralized network, there is also a cryptographic section that is used for data storage processes that make the data secure [3]. However, if these three are combined according to Satoshi Nakamoto in 2008 with an electronic cash system or peer to peer system, then every financial system will be surprised by the findings made by Satoshi Nakamoto because financial systems around the world always follow a centralized ledger, but a system that is run by Satoshi Nakamoto using only finance in a decentralized ledger [4]. This discovery was made not only in theory but with three months of publication on a white paper, therefore Satoshi Nakamoto found his first product using blockchain technology, the name of the product issued was bitcoin, which is the first crypto currency in the world [5]. CNN2 issued news that the price of bitcoin increased from the previous one in 2010 which was 0.08 US \$ then changed to 19891 US $\$$ on 17 December 2017 and on 31 October 2019 the value of bitcoin was 9143 US \$ with existing capital on the market of US \$ 150 billion [6].

The world is terrified by a dramatic change in financial value, so everyone who does business and everyone who knows the greatest invention of this century has to do with bitcoin and the backdrop of blockchain technology [7]. This article not only describes detailed technical knowledge of blockchain technology, but only promotes the capabilities of this blockchain technology to global engineering students [8]. These students need to be aware of more trendy advances and technological changes that contribute a lot to society and provide benefits in the activities of those who use them [9].

In this second part, there are basic concepts and brief insights into the technical aspects of which there are 3 parts, the blockchain has the ability to show use cases from all different fields, of course. Through the use of this case, students will understand that blockchain technology has the strengths and advantages of the blockchain technology concept that applies to every field and not only for cryptocurrencies [10].

\section{Research Method}

The basic basis that blockchain technology has through a simple notebook The first image consists of two images, namely notebook and blockchain and notebooks have several pages that have one way with hardware and software in any way with binding materials. Not with that, the blockchain also has several blocks, which will be joined together with a series of rash codes. Notebook page means the analogy of blocks on the blockchain, both of which have the same purpose of storing all the information that exists [11]. But how are the two different from each other? Everything that's been written on the notes can be easily modified, or deleted pages from the notebook. However, in the case of blockchain, if one person tries to modify or change the contents of the block, the process is invalid, and other nodes will be prohibited [12]. But on $51 \%$ active nodes providing verification, then every move will fail and will destroy the content because the ledger contained on the blockchain cannot be changed because every existing record is hosted in a decentralized network. This record will be guaranteed security because it has been distributed in cryptography so that no third party can modify or damage it [13]. All transactions will be connected to each other which can be verified by the cryptographic process that has been run by the blockchain [14]. The first process in the node is by forming a block in which there are many transactions, after which the block will be immediately verified by the node, then the block that has been verified will be archived by all systems which aim to record evidence of damage or modification by an entity and create unique historical records [15].

There is another feature in this aspect, namely if someone knows the hash code (chain /link) then that person can hijack the information from a certain block. But this crime requires high and strong computing power, but theoretically it will not be possible for the person to need a short time to perform high computing power [16]. In the second analogy, namely how to manage records and the agreement process, in a ledger, the user can manage these records centrally, so that the user does not need to tell the record to all who have notes and even other people cannot know all kinds of changes to the records the [17]. However, the blockchain can share these records with all network nodes on the blockchain so that the process of decentralization and agreement is not one-sided. The consensus mechanism is used in the blockchain and on the PC, working devices that aim to reach an agreement on a single data 
with a state where the network is between distributed frameworks, using this consensus mechanism, it will help in the recording process, this fact is related with a comparison of conventional centralized databases and blockchain-based decentralized databases [18]. In this discussion, it can be defined that blockchain is a "decentralized ledger, which can be modified by the consensus of the majority of nodes". Merriam Webster said that the blockchain is "a digital database which contains information (financial transaction records) that can be used simultaneously and can be shared in a decentralized network, even accessible to the public".

\section{What types of data can the blockchain store?}

is the blockchain only capable of storing financial transactions? No, not at all. Blockchain is capable of storing all types of data on the blockchain, be it personal text documents, photos, videos or any official data, even musical notes too.

\subsection{Components in the blockchain}

Blockchain technology has 6 components in the image below:
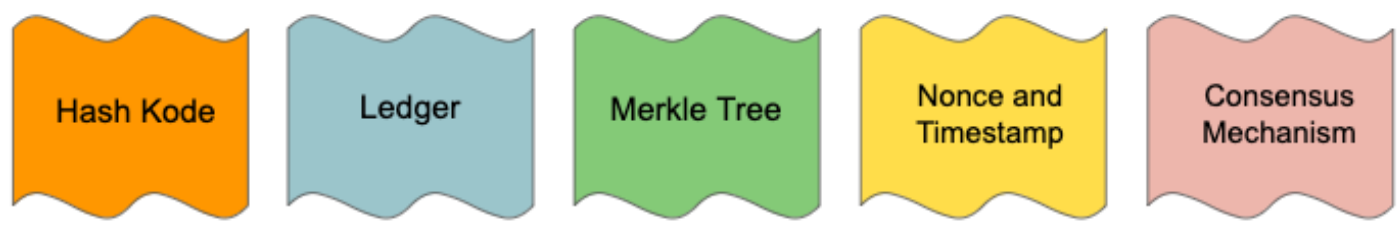

Figure 1. Components on the blockchain

\section{(a). Hash Code}

Hash is a code that is in data on the blockchain. The contents of which are a series of words and letters. A hash function is a mathematical function that takes a variable number of characters and converts it into a string (string) with a fixed number of characters [19]. The hash code on this blockchain is a numeric value that can make it easier to identify objects in general, even this code is issued by a cryptographic process so that this code is unique. Technically, a cryptographic hash function must follow three characteristics in order to be considered safe and effective. We can describe this as the second collision resistance, preimage resistance, and preimage resistance. The hash function itself is usually used for Password Hashing (Hiding Original Passwords) or Digital Signature (digital signature). Commonly used hash algorithms are MD5 and SHA1.

\section{(b). Ledger}

In this ledger is a place for collecting data records that have been stored in blocks, the ledger on this blockchain cannot be managed by one organization or a particular party and when transactions have been recorded in this blockchain ledger, then nothing for anyone can delete the transaction records. Therefore every blockchain is a distributed ledger, but not every distributed ledger is a blockchain. Each of these concepts requires decentralization and consensus between nodes. However, blockchain organizes data in blocks, and updates entries using an append-only structure. The widely distributed ledgers, and blockchain, in particular, represent a conceptual breakthrough in managing information and can be expected to find application in every sector of the economy [20]. 


\section{(c). Merkle Tree}

In particular, the Merkle tree, discovered by Ralph Merkle, is an oriented tree that starts with an even number of outside. This tree is also called leaves. Within the Merkle tree This is a data structure that can be used in cryptography to verify information. This merkle tree is useful in validating the authenticity of the data by comparing the trusted top hash with the untrusted example from the same tree. A practical property of such a construction is that individual branches can be individually checked for integrity without necessarily owning the entire tree or the entire underlying data package. The Merkle tree is used within the blockchain block as an efficient representation of all the transactions that make up that block; this is useful because the block content can then be validated using a single string of fixed length, and there is no need to store all individual transactions [21].

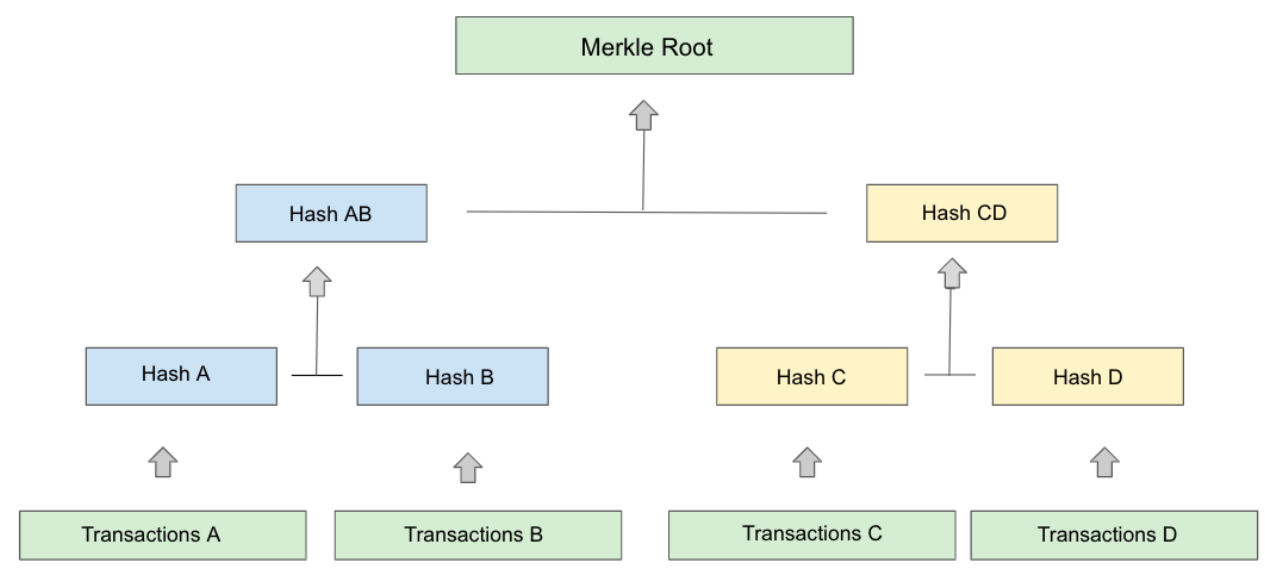

\section{(d). Nonce and Timestamp}

Figure 2. Merkle tree for 4 Hash codes

A nonce is a random pseudorandom number, which can be added to an encrypted block or hash to increase the difficulty level for unauthorized tampering. Every attempt and every transaction is logged with respect to the timestamp, so the record history can be easily filtered [22].

\section{(e). Consensus Mechanism}

From the majority of nodes through which the consensus passes, there is a decision making in blockchain use. It has been systematically calculated that there are $50 \%$, but these blockchain technologies don't have to follow the same rules. For example on $156 \mathrm{G}$, in the case of a private blockchain [23], the user can choose from several other authentications for deal taking. The consensus mechanism that uses the bitcoin blockchain is POW or also known as proof of work. With this POW mechanism, the user can prove that the assigned math puzzle work is usually done before the others and the user has the right to add new transactions to the blockchain. This article will describe some commonly used consensus algorithms such as: Proof of work, ownership, concepts, capacities, interests, proof of weight, proof of delegate ownership, proof of rent, and proof of activity [24].

\subsection{How does Blockchain work?}

How blockchain works is described in Figure 4 with a step by step procedure. There are six different steps from transaction request to transaction settlement. The transaction word used 
here is suitable for all types of applications and everyone who is on the network of a Blockchain can automatically and securely make transactions with one another [25]. The system will verify transactions and enter transaction history into the Blockchain in the form of cryptographic codes [26].

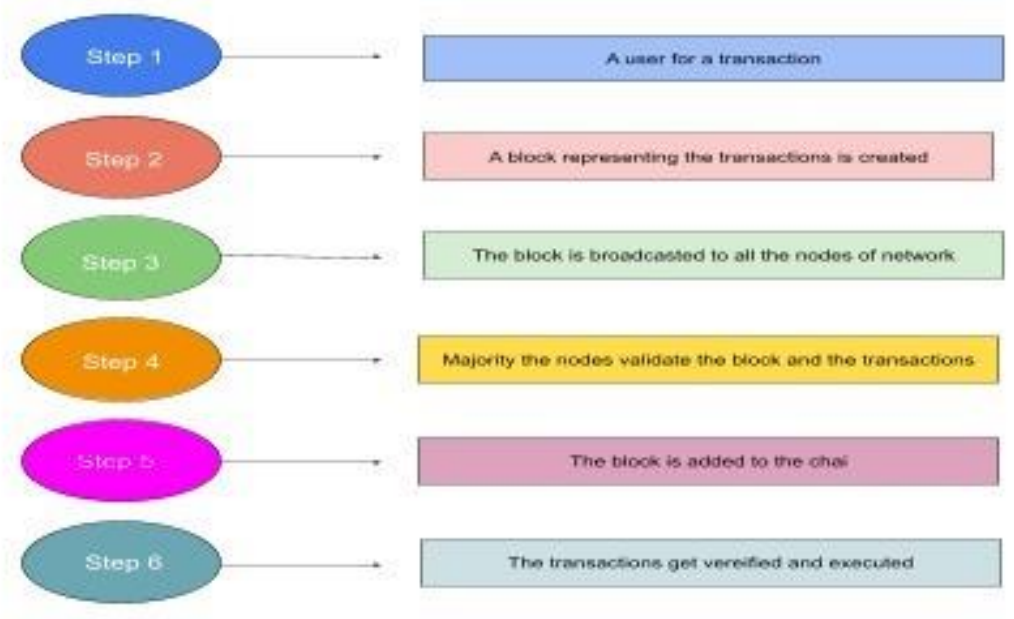

Figure 3. How blockchain works

\section{Result and Discusion}

\subsection{Blockchain Use Cases}

\section{(a). Supply chain management case study: Walmart China}

Unhealthy food can transmit the disease to others. If you want to avoid the disease, a detailed food checking system is needed. Walmart China has an understanding of blockchain and assistance from IBM can develop a blockchain system that is useful for carrying out transparency and efficiency results in supply chain records [27], with this system will help improve food safety and not only that, using this blockchain can track all types of food items. Walmart and IBM developed a global food industry such as Nestle and Unilever, therefore to be able to identify the required global supply chain from the use of blockchain technology [28] [29].

\section{(b). Smart Dubai 2021}

Smart Dubai is a city that has disrupted itself to become a model smart city, which has a strategy of increasing power of change, this city always puts the people first, because the main success is the people. Smart Dubai has prepared an ambitious road map to welcome the future, and Smart Dubai will become a leading city in the world by 2021 , by promoting technological advances that benefit the economy and community resources in the city [30]. Therefore, in this project, Dubai will implement a blockchain system that is broader, blockchain will be implemented in stages in public administration, financial transaction records, data management and even tourism [31]. With this project aimed at developing transparency in administrative security, financial transaction records, data management and increasing efficiency in carrying out processes, then with the completion of this project and successful implementation, Dubai will become the first city in the world to be supported by a blockchain technology system [32]. 


\section{(c). Blockchain-based Know Your Customer: KPMG case study}

Over time, the shopping trend from stores is now changing to a form of e-commerce, which is a buying and selling transaction made with electronic media [33]. Currently, there is a company in the world that has the first computer visual-based technology that is useful for the Know Your Customer process. In KYC there is a disturbance in monitoring financial transactions, by verifying KYC it can help transactions to avoid all money laundering, terrorist crimes, and fraudulent activities [34]. Therefore, to carry out this project KPMG requires 3 banks, namely; HSBC (HongKong Shanghai Bank Corporation), OCBC (Oversea-Chinese Banking Corporation), Mitsubishi UFJ Financial Group and Singapore Regulator. The Singapore IMDA took place between February-May 2017. With this project, it managed to claim such as:

- Can avoid damage to KYC (Know Your Customer).

- Current process for renewal fees in KYC duplication is reduced by $50 \%$.

- More effective and easier monitoring by regulators.

\section{(d). Blockchain for Identity Management: A case study by Johnson Controls International Plc}

A total of 500 produced hardware systems, software in building solutions performed by Fortune companies. The company is implementing blockchain technology that aims to improve the security process of user identity management, to carry out this project, the Fortune company joins the United States-based civic. Because according to Johnson Controls, the new system has the ability to digitally verify identity during the process of entering or leaving someone from the C-CURE 9000 secure building, which does not need to store and collect excessive personal information [35] [36].

\section{(e). Blockchain for Logistics: A case study on maersk}

The application of blockchain technology is a system where records or databases are widespread in the network [37]. With this application, it can help with logistics costs which depend on the complexity of the supply chain of each business actor. Maersk has collaborated with IBM to implement a supply chain with a blockchain technology-based tool that is useful for tracking cargo movements. This collaboration has resulted in a product tool called "Tradelens" which is useful for transparency of contract procedures through the distribution of information on supply and demand [38].

\section{Conclusion}

In the article that has been described above, it has given a brief conclusion about the principle of blockchain, the application capabilities of blockchain have been spread across various sectors, proven to have gone through 6 cases with different uses. This article was created specifically for the purposes of the 2019 WEEF international student forum meeting, therefore the student community needs to be aware of something related to the capabilities of blockchain technology. Because blockchain technology is a technology that is suitable for all groups, students in the world. The author hopes that this article can take lessons about blockchain technology even further, because blockchain technology is a technology that changes the world. Detailed information about this article in each section can be found in the web link listed in the reference section.

\section{References}

[1] S. Nakamoto, "Bitcoin: a peer-to-peer electronic cash system (2008)." 2008.

[2] G. T. Suyambu, M. Anand, and M. Janakirani, "Blockchain-A Most Disruptive 
Technology On The Spotlight Of World Engineering Education Paradigm," Procedia Comput. Sci., vol. 172, pp. 152-158, 2020.

[3] T. M. L. Nguyen, "Utilizing Blockchain to Digitalize Bill of Lading Process at Company X," 2020.

[4] M. Crosby, P. Pattanayak, S. Verma, and V. Kalyanaraman, "Blockchain technology: Beyond bitcoin," Appl. Innov., vol. 2, no. 6-10, p. 71, 2016.

[5] T. T. A. Dinh, R. Liu, M. Zhang, G. Chen, B. C. Ooi, and J. Wang, "Untangling blockchain: A data processing view of blockchain systems," IEEE Trans. Knowl. Data Eng., vol. 30, no. 7, pp. 1366-1385, 2018.

[6] X. Li, P. Jiang, T. Chen, X. Luo, and Q. Wen, "A survey on the security of blockchain systems," Futur. Gener. Comput. Syst., vol. 107, pp. 841-853, 2020.

[7] M. Pilkington, "Blockchain technology: principles and applications," in Research handbook on digital transformations, Edward Elgar Publishing, 2016.

[8] L. W. Cong and Z. He, "Blockchain disruption and smart contracts," Rev. Financ. Stud., vol. 32, no. 5, pp. 1754-1797, 2019.

[9] T. Ahram, A. Sargolzaei, S. Sargolzaei, J. Daniels, and B. Amaba, "Blockchain technology innovations," in 2017 IEEE technology \& engineering management conference (TEMSCON), 2017, pp. 137-141.

[10] J. Yli-Huumo, D. Ko, S. Choi, S. Park, and K. Smolander, "Where is current research on blockchain technology? - a systematic review," PLoS One, vol. 11, no. 10, p. e0163477, 2016.

[11] O. Ali, M. Ally, and Y. Dwivedi, "The state of play of blockchain technology in the financial services sector: A systematic literature review," Int. J. Inf. Manage., vol. 54, p. 102199, 2020.

[12] A. Maharani, S. Aninda, and S. Millah, "Pembuatan Kartu Ujian Online Sebagai Pengabdian Perguruan Tinggi," ADI Pengabdi. Kpd. Masy., vol. 1, no. 2, pp. 8-14, 2021.

[13] Q. Aini, U. Rahardja, and A. Khoirunisa, "Blockchain Technology into Gamification on Education," IJCCS (Indonesian J. Comput. Cybern. Syst., vol. 14, no. 2, pp. 147-158, 2020.

[14] D. Cahyadi, A. Faturahman, H. Haryani, and E. Dolan, "BCS: Blockchain Smart Curriculum System for Verification Student Accreditation," Int. J. Cyber IT Serv. Manag., vol. 1, no. 1, pp. 65-83, 2021.

[15] I. Eyal, A. E. Gencer, E. G. Sirer, and R. Van Renesse, "Bitcoin-ng: A scalable blockchain protocol," in 13th \{USENIX\} symposium on networked systems design and implementation (\{NSDI\} 16), 2016, pp. 45-59.

[16] Z. Fauziah, H. Latifah, X. Omar, A. Khoirunisa, and S. Millah, "Application of Blockchain Technology in Smart Contracts: A Systematic Literature Review," Aptisi Trans. Technopreneursh., vol. 2, no. 2, pp. 160-166, 2020.

[17] F. Agustin, Q. Aini, A. Khoirunisa, and E. A. Nabila, "Utilization of Blockchain Technology for Management E-Certificate Open Journal System," Aptisi Trans. Manag., vol. 4, no. 2, pp. 133-138, 2020.

[18] T.-T. Kuo, H.-E. Kim, and L. Ohno-Machado, "Blockchain distributed ledger technologies for biomedical and health care applications," J. Am. Med. Informatics Assoc., vol. 24, no. 6, pp. 1211-1220, 2017.

[19] C. Di Ciccio et al., "Blockchain-based traceability of inter-organisational business processes," in International Symposium on Business Modeling and Software Design, 2018, pp. 56-68.

[20] R. Beck and C. Müller-Bloch, "Blockchain as radical innovation: a framework for engaging with distributed ledgers as incumbent organization," 2017.

[21] W. Chen, Z. Zheng, M. Ma, P. He, P. Zheng, and Y. Zhou, "Poster: Efficient blockchainbased software systems via hierarchical bucket tree," in 2018 IEEE/ACM 40th International Conference on Software Engineering: Companion (ICSE-Companion), 2018, pp. 360-361.

[22] A. Kehne, J. Schönwälder, and H. Langendörfer, "A nonce-based protocol for multiple authentications," ACM SIGOPS Oper. Syst. Rev., vol. 26, no. 4, pp. 84-89, 1992.

[23] P. Edastama, N. Lutfiani, Q. Aini, S. Purnama, and I. Y. Annisa, "Blockchain Encryption 
on Student Academic Transcripts using a Smart Contract," J. Educ. Sci. Technol., 2021.

[24] Y. P. Tsang, K. L. Choy, C. H. Wu, G. T. S. Ho, and H. Y. Lam, "Blockchain-driven loT for food traceability with an integrated consensus mechanism," IEEE access, vol. 7, pp. 129000-129017, 2019.

[25] J. Hom, B. Anong, K. B. Rii, L. K. Choi, and K. Zelina, "The Octave Allegro Method in Risk Management Assessment of Educational Institutions," Aptisi Trans. Technopreneursh., vol. 2, no. 2, pp. 167-179, 2020.

[26] Q. Aini, N. Lutfiani, and M. S. Zahran, "Analisis Gamifikasi iLearning Berbasis Teknologi Blockchain," ADI Bisnis Digit. Interdisiplin J., vol. 2, no. 1, pp. 79-85, 2021.

[27] I. Noburu, A. Himki, A. Dithi, K. Kano, and M. Anggraeni, "Covid-19: Portrait of Preservation of the Batik Industry as a Regional Autonomy," Aptisi Trans. Technopreneursh., vol. 2, no. 2, pp. 143-152, 2020.

[28] J. Men and G. Balducci, "Prospects and challenges for EU-China relations in the 21st century," PIE Peter Lang, Bruxelles, 2010.

[29] I. Amsyar, E. Christopher, A. Dithi, A. N. Khan, and S. Maulana, "The Challenge of Cryptocurrency in the Era of the Digital Revolution: A Review of Systematic Literature," Aptisi Trans. Technopreneursh., vol. 2, no. 2, pp. 153-159, 2020.

[30] S. Dubai, "Dubai blockchain strategy," Smart Dubai, Dubai Gov. Dec, 2016.

[31] D. Ahmad, N. Lutfiani, A. D. A. R. Ahmad, and U. Rahardja, "Blockchain Technology Immutability Framework Design in E-Government," J. Adm. Publik Public Adm. J., vol. 11, no. 1, pp. 32-41, 2021.

[32] F. Salem, "A Smart City for public value: Digital transformation through agile governancethe case of'Smart Dubai'," World Gov. Summit Publ., 2016.

[33] J. Weber, M. Willenborg, and J. Zhang, "Does auditor reputation matter? The case of KPMG Germany and ComROAD AG," J. Account. Res., vol. 46, no. 4, pp. 941-972, 2008.

[34] A. Kolk, M. L. van der Veen, K. Hay, and D. Wennink, "KPMG international survey of corporate sustainability reporting 2002," 2002.

[35] M. Turkanović, M. Hölbl, K. Košič, M. Heričko, and A. Kamišalić, "EduCTX: A blockchainbased higher education credit platform," IEEE access, vol. 6, pp. 5112-5127, 2018.

[36] A. S. Bein, Y. I. Graha, and A. P. Pangestu, "Pandawan Website Design Based Content Management System As Media E-commerce Transaction," Aptisi Trans. Technopreneursh., vol. 2, no. 1, pp. 87-97, 2020.

[37] I. Ilamsyah, A. Robertz, and R. R. Fitriani, "The Web-based Internet Cafe (RIC) Raharja Ordering System," Aptisi Trans. Technopreneursh., vol. 1, no. 1, pp. 93-100, 2019.

[38] H. Min, "Blockchain technology for enhancing supply chain resilience," Bus. Horiz., vol. 62, no. 1, pp. 35-45, 2019. 